\title{
Accounting for finance is key for climate mitigation pathways
}

\author{
Stefano Battiston ${ }^{1,2}$, Irene Monasterolo ${ }^{3,4}$, Keywan Riahi ${ }^{5,6}$, Bas J. van Ruijven ${ }^{5}$ \\ 'Department of Banking and Finance, University of Zurich, Zurich, Switzerland. 'Department of Economics, Ca' Foscari University of Venice, Venice, Italy. ${ }^{3}$ Vienna University \\ of Economics and Business, Vienna, Austria. ${ }^{4}$ Global Development Policy Center, Boston University, Boston, MA, USA.. International Institute for Applied Systems Analysis \\ (IIASA), Laxenburg, Austria. ${ }^{6}$ Graz University of Technology, Graz, Austria. Email: stefano.battiston@uzh.ch
}

Investors' expectations can hamper a low-carbon transition

The financial system - the ecosystem of investors (e.g., banks, investment funds, insurance), markets, and instruments-is often considered to play an enabling role in climate mitigation pathways to a low-carbon transition (1). But it can also have a hampering role, e.g., if investors' perceptions of low risk from a missed transition and low opportunities from a transition fail to trigger a reallocation of capital into low-carbon investments. This increases the chance of the transition not occurring within the time window required to stabilize the climate or occurring in a disorderly fashion. Indeed investors, who can influence the realization of climate mitigation pathways, themselves rely on estimates of climate mitigation pathways from process-based integrated assessment models (IAMs) (2). And IAMs do not model the financial system or investors' decisions; thus, the feedback loop between the financial system and mitigation pathways is not taken into account, neither by the IAMs nor by the finance community. This limitation to our understanding of the dynamics and the feasibility of the low-carbon transition weakens the ability of IAMs to inform policy and investment decisions. We propose a framework to capture the interdependence between investors' perception of future climate risk, depending on the credibility of climate policies, and the allocation of investments in the economy.

\section{CLIMATE MITIGATION SCENARIOS}

Process-based, large-scale IAMs are used to develop longterm emission projections and socioeconomic scenarios assessed by the Intergovernmental Panel on Climate Change (IPCC) (1). Scenarios are constructed to suggest how to reach given targets in terms of cumulative emissions (and thus in terms of carbon budget) by 2100 , which translate into temperature targets with associated probabilities. The IAM literature, assessed by the IPCC, produced a set of archetypical climate mitigation scenarios representing the most distinct features of how the transition could happen in the next decades. This is where the notion of risk is key. Whereas investors' preferences differ in terms of risk aversion and investment strategies, they all make investment decisions based on their assessment of risk.
In 2019, the Network of Central Banks and Supervisors for Greening the Financial System (NGFS), a global platform of more than 80 financial authorities, recognized that climate change poses new risks for citizens' investments and savings. It recommended a climate risk assessment of financial portfolios using several high-level scenarios (3), including (i) an orderly transition, in which climate policies are introduced early and predictably and climate risks are priced in by financial markets; and (ii) a disorderly transition, in which the impact of climate policies is not (fully) anticipated by investors. In the first case, firms have time to plan ahead and investors to reallocate capital gradually. In the second case, high-carbon firms and investors face losses that can trigger market instability and costs for society as a whole. High-carbon firms would lose out in both situations, and more so in the disorderly scenario. By contrast, low-carbon firms would benefit in both situations, but not necessarily more in the disorderly scenario.

To translate these scenarios into quantitative trajectories of economic variables, the NGFS and a growing number of investors already use the output of process-based IAMs as an input for climate financial risk analysis (4). These scenarios, describing what the world might look like several years from now, have the power to shift markets' expectations today, because they are endorsed by the NGFS and large investors. It is thus critical to understand if these scenarios for potential tomorrows could lead, unintentionally, to insufficient investments today, owing to their not accounting for the role of financial actors themselves. Our framework addresses this challenge and allows us to derive scenarios that complement the current IPCC and NGFS scenarios, strengthening climate financial risk assessment.

Firms and consumers' responses to climate policies are endogenous to the IAMs and have long been investigated (5). But the ways in which investors' responses to climate policies affect the outcome of those policies have not been investigated in IAMs and are not well understood (6). Indeed, IAMs [including large-scale computable general equilibrium models (7)] consider "finance" only to the extent that firms' access to financing is assumed to be available at no cost and with no 
limits (8). They overlook that financing is provided by investors on the basis of assessed risk, resulting in financing costs and limits on funding. IAMs include no actors (e.g., banks) that can decide to grant loans to firms, or actors (e.g., insurance firms, pension funds) that can decide to invest (or not) in stock market shares of firms. This leads to the opportunity to interface IAMs with models where investors carry out a financial risk assessment.

\section{AN ENABLING OR HAMPERING ROLE OF THE FINANCIAL SYSTEM}

Consider a utility firm that seeks financing to shift its power plants from high- to low-carbon technologies. If a bank perceives the strategy as less (more) risky than staying on highcarbon technologies-because the climate policy, e.g., a carbon price, is perceived as credible (non credible)-it will soon charge a lower (higher) interest rate on the loan, thus facilitating (delaying) the firm's technological conversion. In general, if investors start to perceive high risk from a missed transition, and, conversely, high opportunities from a successful transition with credible climate policies (9), they adjust their expectations. They thus reallocate capital into lowcarbon investments early and gradually and can even anticipate the policy impact, as described by the notion of climate sentiments (10). This "enabling" behavior facilitates the transition, because it leads to smoother adjustments of the economy and of prices. If, by contrast, investors' perception goes in the opposite direction, they react late and suddenly. This "hampering" behavior makes the transition more costly for society, because it can lead to abrupt reallocations of capital and price adjustments. The enabling or hampering roles of the financial system can explain how the orderly and disorderly transition emerges from the interplay of policy timing and investors' reactions.

Overall, the presence of the financial system may induce a path dependence in the complex dynamics leading to lockin effects similar to those described in models of technology diffusion. In particular, transition trajectories could differ from those described by IAMs' scenarios because IAMs only consider technology cost and not the financing costs-nor investors' reactions-to deploy such technologies. For instance, investors could interpret NGFS scenarios of orderly transition as a situation in which high-carbon firms are only slightly more risky than low-carbon ones, because firms can adjust their technology mix and spread over time losses arising from stranded assets, i.e., unusable high-carbon installations (11). Driven by this risk perception, investors could play a hampering role and only reallocate capital from high- to low-carbon firms to a limited extent. It is not guaranteed that this level of reallocation is sufficient to fund investments in low-carbon energy that this scenario assumes; a low-risk perception induced by the orderly scenario could make the scenario unfeasible in the real world.

By contrast, investors could interpret a scenario of a disorderly transition as a situation in which high-carbon firms become substantially more risky than low-carbon ones, following the introduction of stringent carbon prices. For instance, high-carbon energy firms have an incentive to delay their own conversion, but owing to increasing public and investor demand, politicians could eventually find an agreement to introduce stringent climate policies. Because of the opposing interests in the negotiation, this could happen at the last moment. Investors who want their portfolio to withstand such an outcome could play an enabling role and start to demand a higher interest rate from high-carbon firms well before the policy introduction. They would reallocate capital to low-carbon firms to hedge the risk (if they continue to have a preference for lower risk). Thus, the capital reallocation, driven by risk perception, could lead to investments in lowcarbon firms that increase earlier and at higher levels than those assumed in the scenario, and hence to larger mitigation opportunities. Furthermore, the financial feedback on firms' investment decisions can also lead to cascading effects in the economy. To some extent, this is precisely what the disorderly scenario is meant for: to allow an assessment of risk by investors in order to avert the realization of the scenario itself. This should not come as a surprise, in the same way that requiring buildings' owners to consider fire scenarios is ultimately meant to avoid the adverse scenario.

Possible inconsistencies between the investment levels in the original IAMs' scenarios and those resulting from the role of the financial system motivate the need for a new framework to connect climate mitigation scenarios and financial risk assessment in a circular way.

\section{CONNECTING MITIGATION SCENARIOS AND FINANCIAL RISK ASSESSMENT}

The use of IAM scenarios to assess climate-related financial risks has been introduced by academic work on the climatestress test of the financial system (12), and in recent applications to central banks' data (13). It consists of translating IAMs' output trajectories across technologies (e.g., fossil fuels and renewables) and scenarios into financial shocks on investors' portfolios. Combined with financial network models, it also captures the amplification of shocks through financial interconnectedness and the implications for individual and systemic financial stability. We refer to this approach as the climate financial risk (CFR) model.

In IAMs, the decision of firms on how many energy plants of a given technology to build is determined by the carbon pricing. The financing costs and the fact that they vary with the risk attributed to technologies by investors is not taken into account but can be obtained from a CFR model.

We propose a general framework (see the first figure) to 
link IAMs and CFR in a circular way, which can be embodied with different choices of specific IAMs and CFR models. The IAM module generates sets of climate mitigation scenarios, which are then used by the CFR to model how investors assess the financial risk of high- and low-carbon firms along the IAM's trajectories. If investors assess a higher risk for highcarbon firms, they demand higher interest rates on loans, and higher yields for bonds, to provide funding. They may also divest from some high-carbon firms to reinvest in low-carbon firms in order to balance their portfolio risk. The resulting trajectories of financing cost across low- and high-carbon firms are fed back to the IAMs to update the respective mitigation scenarios, thus closing the loop between the IAM and the CFR.

Such IAM-CFR scenarios can demonstrate the interplay between the role of the financial system (enabling or hampering) and the timing of the climate policy introduction (see the second figure for a stylized illustration), the latter being identified by the IPCC as a key dimension of climate mitigation. We condition the analysis to a temperature target of $2^{\circ} \mathrm{C}$, in line with the Paris Agreement, but other scenarios can be analyzed. On the basis of the IPCC and NGFS scenarios, we consider two options for the timing of policies. The immediate case focuses on 2020 [based on (1)], but results would be similar for 2021 or 2022 . The delayed case focuses on 2030 , because a transition that starts later than 2040 is considered not compatible with the $2^{\circ} \mathrm{C}$ target.

All IAMs share the general result that, in a transition scenario that achieves a $2^{\circ} \mathrm{C}$ target, the output (energy production) of high-carbon activities starts to decline at the introduction of the policy, and the reverse applies for lowcarbon activities. Although quantitative details of output trajectories vary across IAMs, the solid curves in the second figure represent this common stylized behavior.

In the enabling cases (see the second figure, top panels), investors start to demand higher interest rates for high-carbon firms at the introduction of the policy, or even earlier (and lower interest rates for low-carbon firms). In the IAMCFR scenarios, output of high-carbon firms must be lower than in the original IAM-only scenarios where only the carbon tax is considered (the reverse for low-carbon firms). This is due to financing costs, which are additional to the carbon tax and enhance the differences in profitability of firms across technologies. Accordingly, the values of assets of highcarbon firms decrease gradually and those of low-carbon firms increase gradually.

Investors' expectations are the key feature that sets the system to an enabling or a hampering role of the financial system. Because expectations are subject to herding dynamics whereby investors try to guess each other's next move, a stampede can occur unexpectedly (e.g., the 2008 subprime mortgage crisis). In the hampering cases (see the second figure, bottom panels), investors delay revising their expectations, but then expectations change suddenly. This results in output trajectories that increase (or decrease) at a faster pace than in the cases without CFR, as trajectories have less time to meet the same carbon budget. Financial asset values also adjust suddenly. The adjustment has to occur before 2040, otherwise the $2^{\circ} \mathrm{C}$ target is missed.

In the NGFS scenarios, the orderly versus disorderly character of scenarios is assumed, independently of the role of the financial system. Here we show two cases where the financial system can largely modify the outcome of those scenarios. First, an immediate transition to $2^{\circ} \mathrm{C}$ is classified in the NGFS scenarios as orderly. If, however, the financial system plays a hampering role (see the second figure, bottom left panel), the transition is delayed and there are large and sudden financial value adjustments. These features threaten financial stability and would be more consistent with a disorderly scenario. Second, a delayed transition to $2^{\circ} \mathrm{C}$ is classified there as disorderly. If the financial system plays an enabling role (see the second figure, top right panel), the gradual price adjustments along the trajectory would be more consistent with an orderly NGFS scenario. Finally, a disorderly transition could also lead to higher risk than described in the NGFS disorderly scenario, if the financial system plays a hampering role. Neglecting the role of the financial system could thus lead to overestimate or underestimate risk across NGFS scenarios.

\section{CONCLUSION AND POLICY IMPLICATIONS}

Our approach opens the way to a new understanding of risks and opportunities associated with the low-carbon transition. By conditioning the investment decision of investors to the credibility of climate policy scenarios, we consider the role of the financial system as enabling or hampering the low-carbon transition. This could reverse the ordering of costs and benefits of climate mitigation policies, which are currently distorted by not considering the financial system.

Such analyses can provide new insights on the implementation of fiscal policies, such as carbon pricing and the phasing out (in) of fossil fuel (renewable energy) subsidies. Neglecting the role of finance implies that a projected carbon price schedule could miss the emissions target because the mitigation scenario does not necessarily imply a risk perception by the financial system that leads to the investment reallocation assumed by the scenario. Similarly, plans for phasing out carbon subsidies have an impact on the perception of risk by the financial system with regard to high-carbon technologies. Thus, our framework could help the IPCC community to revise their carbon price projections obtained from climate mitigation models to make them more consistent with the role that the financial system plays.

Our framework could also support financial authorities in encouraging investors' assessment of climate-related 
financial risk. The IAM-CFR scenarios would limit the underestimation of financial risk in climate stress-test exercises. Accounting for the role of the financial system also has implications for criteria used by central banks to identify eligible assets in their collateral frameworks and purchasing programs. Furthermore, our results illustrate the need for financial authorities to monitor and tame the possible moral hazard of the financial system in the dynamics of the lowcarbon transition.

\section{REFERENCES AND NOTES}

1. IPCC, "Global warming of $1.5^{\circ} \mathrm{C}$. An IPCC Special Report on the impacts of global warming of $1.5^{\circ} \mathrm{C}$ above pre-industrial levels and related global greenhouse gas emission pathways" (2018); www.ipcc.ch/sr15/.

2. J. Weyant, Rev. Environ. Econ. Policy 11, 115 (2017). doi:10.1093/reep/rew018

3. D. McCollum et al., Nat. Energy 3, 589 (2018).

4. I. Keppo et al., Environ. Res. Lett. 16, 053006 (2021). doi:10.1088/17489326/abe5d8

5. Network for Greening the Financial System (NGFS), "Guide for Supervisors Integrating climate-related and environmental risks into prudential supervision" (2020); www.ngfs.net/en/guide-supervisors-integrating-climate-related-andenvironmental-risks-prudential-supervision.

6. UNEP-FI, "Decarbonisation and Disruption: Understanding the financial risks of a disorderly transition using climate scenarios" (2021); www.unepfi.org/publications/banking-publications/decarbonisation-anddisruption/.

7. Y. Chen et al., The MIT Economic Projection and Policy Analysis (EPPA) Model: Version 5. Joint Program Technical Note TN \#16, March (2017); http://globalchange.mit.edu/publication/16620.

8. H. Pollitt, J.-F. Mercure, Clim. Policy 18, 184 (2018). doi:10.1080/14693062.2016.1277685

9. K. S. Rogge, E. Dütschke, Environ. Sci. Policy 87, 74 (2018). doi:10.1016/i.envsci.2018.05.009

10. N. Dunz, A. Naqvi, I. Monasterolo, J. Financ. Stab. 54, 100872 (2021). doi:10.1016/j.jfs.2021.100872

11. C. McGlade, P. Ekins, Nature 517, 187 (2015). doi:10.1038/nature14016 Medline

12. S. Battiston, A. Mandel, I. Monasterolo, F. Schütze, G. Visentin, Nat. Clim. Chang. 7, 283 (2017). doi:10.1038/nclimate3255

13. A. Roncoroni, S. Battiston, L. O. L. Escobar-Farfán, S. Martinez-Jaramillo, J. Financ. Stab. 54, 100870 (2021). doi:10.1016/j,jfs.2021.100870

\section{ACKNOWLEDGMENTS}

S.B. received funding from the foundation $\mathrm{G}+\mathrm{B}$ Schwyzer-Winiker-Stiftung. I.M. received funding from the 11th ACRP call project GreenFin (grant agreement no. KR18ACOK14634) and from the European Union's Horizon 2020 research and innovation programme under grant 821010 (CASCADES). K.R. and B.J.v.R. received funding from the European Union's Horizon 2020 research and innovation programme under grant agreement 821471 (ENGAGE).

Published online 20 May 2021

10.1126/science.abf3877 


\section{Linking climate mitigation pathways and the financial system}

An integrated assessment model (IAM) generates economic output trajectories under climate policy scenarios. A climate financial risk (CFR) model uses IAM output to compute interest rates for firms using different energy technologies ( $k$ ). Investors' expectations and climate value-at-risk (ClimateVaR) determine capital allocation across technologies. The IAM updates to reflect diversity in financing costs.

\begin{tabular}{|c|c|c|}
\hline IAM & & CFR \\
\hline $\begin{array}{c}\text { Carbon price } \\
p_{s}(t)\end{array}$ & $\begin{array}{l}\text { IAM to CFR } \\
(p, I, Y)\end{array}$ & $\begin{array}{c}\text { Investor expectations } \\
\beta(t)\end{array}$ \\
\hline $\begin{array}{c}\text { Investment } \\
L(t)=I^{(\mathrm{AMM})}(p(t))+\Delta l^{(\mathrm{CFR})}(r \quad(t))\end{array}$ & & $\begin{array}{c}\text { Interest rate } \\
r_{s,(Y}\left(Y_{s k}(t), p_{s}(t), \beta(t)\right)\end{array}$ \\
\hline $\begin{array}{c}\text { Output } \\
Y_{s, k}\left(I_{s, k}(t), p_{s}(t)\right)\end{array}$ & $\begin{array}{l}\text { Output from } \\
\text { CFR to IAM }\end{array}$ & $\begin{array}{c}\text { Capital allocation } \\
h\left(\operatorname{ClimateVaR}_{\left(Y_{s, k}(t), \beta(t)\right)}\right.\end{array}$ \\
\hline
\end{tabular}

Interplay between the financial system and climate policy timing Four main climate transition scenarios are shown. Solid curves are the same in top and bottom panels and represent stylized trajectories from existing integrated assessment model (IAM) scenarios of electricity production from coal or renewable energy. Dashed curves represent stylized trajectories from the IAM-climate financial risk (CFR) framework of electricity production and asset values. The difference between solid and dashed curves is the effect of accounting for the role of the financial system.

\section{Trajectories from IAM scenarios Trajectories from IAM-CFR framework \\ - Renewable energy - Coal - - Renewable energy -- Coal}

Immediate climate policy
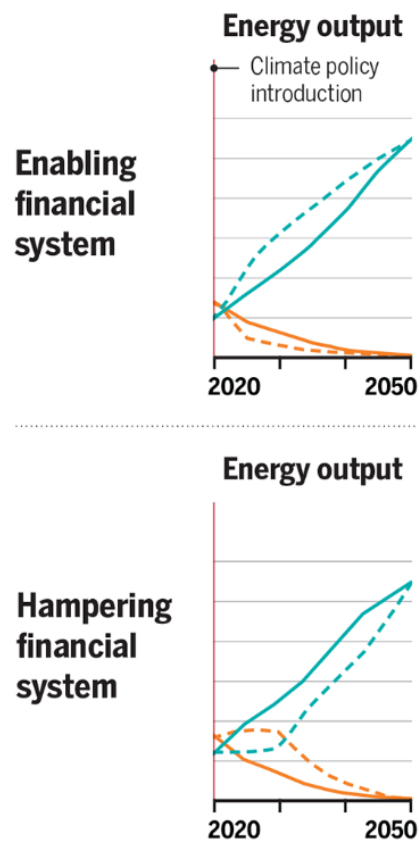
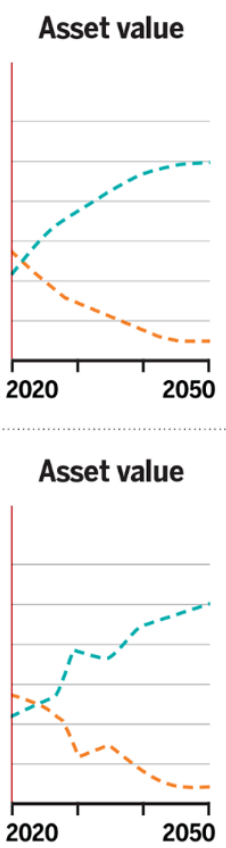

\section{Delayed climate policy}
